\title{
AN IMPORTED AUSTRALIAN VIRUS FOR THE CONTROL OF PAINTED APPLE MOTH
}

\author{
J. POULTON ${ }^{1}$, V.K. WARD ${ }^{2}$, T.R. GLARE ${ }^{3}$ and N.P. MARKWICK ${ }^{1}$ \\ ${ }^{1}$ HortResearch, Private Bag 92196, Auckland, New Zealand \\ ${ }^{2}$ University of Otago, PO Box 56, Dunedin, New Zealand \\ ${ }^{3}$ AgResearch, PO Box 60, Lincoln, New Zealand
}

Corresponding author:jpoulton@hortresearch.co.nz

Teia anartoides, the Painted Apple Moth (PAM), has been the subject of an extensive eradication programme in Auckland. As part of a MAF-funded programme to increase the tools available for eradication, microbial pathogens of PAM are being investigated. One of these, Orygia [=Teia] anartoides nucleopolyhedrosis virus (OranNPV) was imported into New Zealand from Australia in 2004, for pathogenicity and host-range testing in containment. Three isolates tested were highly pathogenic to $3^{\text {rd }}$ instar PAM. All infected larvae died at PIB concentrations of $10^{4}$ and $10^{5}$ /larva but mortality was more variable at lower concentrations. The LT50 decreased with increasing dose, from an average across the three isolates of 8.2 days at $10^{5} \mathrm{PIBs} /$ larva to 15.1 days at $10^{2}$ PIBs/larva. Larvae of 13 common New Zealand lepidopteran species, inoculated with one OranNPV 'isolate,' showed no effects on survival to pupation, larval growth or pupal weight. Survival of adult honeybees (Apis mellifera) was also not affected by the virus. PCR-based sequence analysis of a 317 bp region of the polyhedrin gene has shown the three isolates are identical in this region and all show a mixture of two identical single sequence polymorphisms in 30 of 31 sequenced polyhedrin sequences derived from individual infected insects.

\section{TIPPING THE SCALES IN YOUR FAVOUR: PREPARING COMPREHENSIVE ERMA APPLICATIONS}

\author{
S.A. WHITEMAN and G.S. RIDLEY
}

\author{
ERMA New Zealand, PO Box 131, Wellington
}

\section{Corresponding author: sonia.whiteman@ermanz.govt.nz}

The introduction of a biological control agent (BCA) that is a new organism is regulated by the Environmental Risk Management Authority (ERMA) New Zealand under the Hazardous Substances and New Organisms (HSNO) Act 1996. The purpose of this poster is to provide guidance for researchers on, and an opportunity to discuss, the preparation of comprehensive release applications. The level of detail required and quality of a comprehensive application is similar to that found in a funding proposal or scientific paper. Clear evidence on the risks, costs and benefits substantiated with sound scientific data and logical arguments about the level of uncertainty should be presented. To gain approval applicants need to demonstrate that any risks or costs associated with the release of a BCA are outweighed by the benefits. The potential adverse effects associated with the release of a BCA generally arise from impacts on non-target organisms. It is vital that applicants explain the rationale and outcome of the host-specificity testing. Proof of benefits often hinges on demonstrating the ability of the BCA to establish and to be effective against the chosen host. Sources of information to help with the preparation of applications will be provided. 